\title{
DISCUTINDO O RURAL E O URBANO
}

\author{
Discussing the Rural and the Urban
}

Prof. Dr. José Borzacchiello da Silva

Pós-Graduação em Geografia da Universidade Federal do Ceará Campus do Pici, Bloco 911, CEP 60.455.760, Fortaleza (CE), Brasil Tél : (+ 55 85) 33669855 - borza@estadao.com.br

\section{$a_{a} \boldsymbol{a}_{a}$}

\begin{abstract}
Resumo
O artigo privilegia as novas releituras do papel histórico da cidade e suas relações com o campo. Discute o rural e o urbano em torno de temas versando sobre novo rural, nova ruralidade, inovação do rural face à uma reorganização da urbanização. $\mathrm{O}$ enfoque considera os novos arranjos espaciais decorrentes da intensificação das redes. Constata a proliferação de teses confirmando o fim do rural e do agrário, bem como aquelas que foram retomadas fundadas no pressuposto da subordinação do campo face às inovações do urbano/industrial. Parte do pressuposto traz um enfoque mais ligado à forma que ao processo e que caíram por terra as teses calcadas nas formulações sobre o fim do rural firmadas diante da modernização da agricultura, da industrialização do campo, da revolução verde e da emergência do agronegócio etc. Insiste na necessidade do debate acadêmico envolvendo diferentes áreas do conhecimento indicando novas pistas. Aponta que o avanço do enfoque explicativo dos novos arranjos exige a transposição de barreiras e preconceitos. Considera que no Brasil a abordagem tradicional de campo e cidade, de rural e de urbano, trata estas espacialidades como distintas.
\end{abstract}

Palavras-chave: Rural, Urbano, Modernização, Transformações.

\begin{abstract}
This paper focuses on the new readings of the historic role of the city and its relationships with the countryside. It discusses the rural and the urban in the context of themes such as the new rural, new rurality, and the innovation of the rural as a response to the re-organization resulting from urbanization. This focus considers the new spatial arrangements derived from the intensification of networks. An increasing number of theses have confirmed the end of the rural and the agrarian, while others have been based on the assumption that the countryside has become subordinated to the innovations of the urban and industrial spheres. This is derived from the assumption that the approach is linked more to the form than the process, which has undermined the theses based on the prediction of the end of the rural resulting from the modernization and industrialization of agriculture, the green revolution, the emergence of agribusiness and so on. There is thus a clear need for academic debate involving different areas of research, which may provide new insights. The increasing focus on the interpretative perspective of the new arrangements demands that barriers and preconceptions be overcome. In Brazil, in particular, the traditional approach of countryside and city, rural and urban, treats these specializations distinctly.
\end{abstract}

Key words: Rural, Urban, Modernization, Transformations.

\section{Resumen}

El artículo privilegia las nuevas relecturas del papel histórico de la ciudad y de sus relaciones con el campo. Discute lo rural y lo urbano en torno de temas versando sobre lo nuevo rural, la nueva ruralidad, innovación de lo rural de cara a una reorganización de la urbanización. El enfoque considera los nuevos arreglos espaciales recurrentes de la intensificación de las redes. Proliferándose tesis confirmando el fin de lo rural y de lo agrario, bien como aquellas que fueron retomadas fundadas en el presupuesto de la subordinación del campo de car a las innovaciones de lo urbano/industrial. Parte del presupuesto que el enfoque está más ligado a la forma que el proceso y que caerán por tierra las tesis fundamentadas en las formulaciones sobre el fin de lo rural firmadas la modernización de la agricultura, industrialización del campo, revolución verde y la emergencia del agronegócio etc. Insiste en la necesidad del debate académico envolviendo diferentes áreas de conocimiento apuntado nuevas pistas. Apunta que el avance del enfoque sobre la perspectiva explicativa de los nuevos arreglos exige la transposición de barreras y prejuicios. Considera que en Brasil el abordaje tradicional del campo y la ciudad, de lo rural y de lo urbano, trata estas espacialidades como distintas. Reconoce que esa discusión ultrapasa los limites nacionales, en la tentativa de identificar nuevos arreglos socio-espaciales.

Palabras claave: Rural, Urbano, Modernización, Transformaciones.

\section{aaAaa}




\section{INTRODUÇÃO}

A discussão enfocando temas como o novo rural, nova ruralidade e inovação do rural, tem sido recorrente. No Brasil a abordagem tradicional de campo e cidade, de rural e de urbano, trata estas espacialidades como distintas, com reduzidos pontos de ligação, enfoque que está mais ligado à forma que ao processo. As teses calcadas no pressuposto do fim do rural firmadas face à modernização da agricultura, a industrialização do campo, a revolução verde e a emergência do agronegócio etc., caíram por terra. O debate acadêmico envolvendo diferentes áreas do conhecimento tem apontado novas pistas, embora se prolongue interminavelmente. A discussão persiste não só no Brasil, mas também no mundo. Por exemplo, a dinâmica demográfica atual comprova uma intensa transferência da população do campo para a cidade sem provocar, no entanto, o esvaziamento demográfico do meio rural.

No campo específico da geografia, constata-se um distanciamento entre as disciplinas Geografia Agrária e Geografia Urbana, prejudicando um diálogo necessário e, certamente, profícuo. Nos momentos de aproximação entre as duas disciplinas, quando da abordagem do processo, percebe-se mais a apreensão do movimento da passagem do campo para a cidade, pautada na atividade do trabalhador rural que chega à cidade na condição de migrante. Na perspectiva teórica da geografia, o que se cobrava era uma abordagem dos sujeitos sociais envolvidos no processo de produção do espaço seja ele rural ou urbano. Há um forte pressuposto acreditando que o urbano só se explica a partir do rural. Harvey (1980) pautado na dialética marxista, discute a teoria do excedente obtido na economia agrária para explicar os pressupostos da formação da cidade e do urbano como locus da acumulação. A discussão está posta. Resta transpor a querela capaz de romper as fronteiras impostas entre os espaços urbanos e rurais.

No que tange à realidade espacial brasileira, evidencia-se a formação de extensas periferias urbanas, o que, anteriormente, era um fenômeno restrito às grandes cidades. Hoje, processo análogo acontece em cidades médias e mesmo pequenas tornando a periferização uma configuração urbana expandida, presente, praticamente, em território urbano nacional. Sua presença denota uma situação de precariedade e déficit de políticas públicas mais abrangentes que atingem os setores de infra-estrutura, equipamentos e serviços nas áreas do saneamento básico, habitação, saúde e educação. Configuram paisagens reveladoras das diferenças estruturais que explicam os contrastes sociais brasileiros. Como agravante, a sociedade lida com a violência urbana que desponta como um problema social generalizado, atingindo o campo e a cidade. $\mathrm{O}$ crescimento acentuado da população urbana do país amplia a lista das grandes cidades. Em 1940 constituía apenas 31\% da população total. Na década de 50 o crescimento econômico atingiu patamares de $10 \%$ ao ano. Nos anos 60 diminuiu e no início dos 70 voltou ao patamar dos 50. A partir de 74 voltou a diminuir até a bancarrota da "década perdida" 80/90.

Quatro décadas depois esse percentual chega a 75\%. Além do mais, a população tende cada vez mais a se concentrar nas aglomerações urbanas. Para se ter idéia da complexidade dessa dinâmica demográfica, documento da CNBB, já apontava o problema e assim se manifestava: "Hoje, em 13 concentrações urbanas moram $32 \%$ da população total o que representa metade da população urbana". No atual contexto, conforme os resultados do Censo Demográfico do IBGE de 2010, 84\% da população reside em áreas urbanas.

Entre nós as questões voltadas à definição e diferenciação entre o rural e o urbano são antigas. Em obra clássica da literatura geográfica brasileira, Azevedo (1970, p. 221) afirma "Não é fácil quanto possa parecer a fixação das áreas urbanizadas em nosso país. Antes de mais nada, devemos enfrentar um problema essencial: o que se deve considerar urbano e, mais ainda, qual o critério para distinguir uma aglomeração urbana de uma aglomeração rural". A inquietação do autor refere-se a um período de acentuado aumento demográfico da população brasileira e de intenso fluxo migratório campo-cidade. Trata-se de um momento de consolidação da realidade urbana e metropolitana do país, especialmente na região Sudeste. 
No final do século XX presencia-se um movimento caracterizado pela rápida integração de mercados e circulação acelerada de mercadorias interligando as diversas regiões do mundo, reduzindo sensivelmente o tempo de fricção entre as distâncias. Instaura-se, segundo os economistas, a globalização, expressão do estágio atual do processo de expansão capitalista. As cidades assumiram papel impar como lócus da acumulação, pólos de produção e difusão tecnológica e centros reguladores de preços, de bolsas de valores e de grandes transações comerciais. Para atender à demanda ampliada, muitas cidades se refuncionalizaram e se requalificaram. Essa reorganização da urbanização mundial inserida na sociedade de redes provocou uma releitura do papel histórico da cidade e suas relações com o campo. Foram muitas as teses confirmando o fim do rural e do agrário retomando as teses da subordinação do campo aos ares inovadores do industrial e do urbano. A reação foi imediata. Não tardaram estudos e discussões enfocando as singularidades do mundo rural.

Vários eventos acadêmicos importantes como o Simpósio Nacional de Geografia Urbana, o Simpósio Internacional de Geografia Agrária e o Encontro Nacional de Geografia Agrária, têm se constituído em espaços privilegiados de discussão com o objetivo de contribuir para o aprofundamento dos debates realizados sobre o rural, o urbano, o campo e a cidade no Brasil. Eles incorporam a tradição da reflexão geográfica dando lugar a novas matrizes de leituras destas realidades socioespaciais, considerando, principalmente, temas norteadores que abordam questões sobre o campo e a cidade brasileira do passado, enfrentando sérios dilemas na conceituação de cidade e de urbano e de campo e de rural.

Os estudos tradicionais focados na temática do rural e do urbano remetem aos conceitos de tradicional e de moderno, respectivamente. Na abordagem clássica o rural é definido como um espaço associado às atividades que mantém relações diretas com a natureza. Quanto à forma, sua organização apresenta a dispersão da população. O urbano o contrário, se caracteriza por uma complexa organização, tendo na concentração populacional sua principal marca. É visto ainda como locus da divisão do trabalho e da concentração do capital.

Cidade e processo de urbanização decorrente são elementos essenciais na reestruturação e reterritoriarização do espaço, elementos centrais nas políticas de desenvolvimento regional. A cidade vista historicamente como local de liberdade, de novo modo de vida, de inovações e do moderno ajusta-se às novas funções acomodando seu papel de centro de comando. No Brasil, o desenvolvimentismo, enquanto meta oficial alterou substancialmente o espaço brasileiro. A alocação de recursos fora do Sudeste, região tradicional do país, a política do rodoviarismo e a transferência da capital do Rio de Janeiro para Brasília modificaram e inverteram significativamente os fluxos migratórios, provocando grandes mudanças internas no país nos últimos 50 anos. No Centro Sul do Brasil, é atribuído à industrialização, papel propulsor da proliferação de cidades e instauração de um modo moderno de vida urbano. Entre nós ainda são insatisfatórias as fronteiras teóricas que tentam explicar as diferenças e conceituar o que é urbano e o que é rural.

Retomando os resultados do último Censo Demográfico do IBGE de 2010, constata-se um elevado percentual, ou seja, $84 \%$ da população residindo em áreas urbanas. Entretanto, independente do percentual, permanecem muitas as querelas que envolvem a discussão em torno da definição do que é rural e do que é urbano. Qual seria o cerne dessa discussão? Como estabelecer limites e fronteiras? Como tratar as áreas de sombreamento, de transição entre o rural e o urbano? Antes de mais nada, a capacidade de discernir o que é rural e o que é urbano torna-se fundamental para a formulação de políticas públicas de forte rebatimento e impacto social. São procedimentos fundamentais no estabelecimento de políticas tributárias no que tange à cobrança de impostos, taxas, tarifas, contribuição de melhoria, concessão de incentivos e permite a distinção entre os que pagam e os que se beneficiam. 


\section{O RURAL E O URBANO}

A qualidade de vida no campo e na cidade está intimamente ligada às políticas públicas voltadas para o bem estar social, compreendendo itens ligados à densidade demográfica, configuração da paisagem, levantamento de necessidades e estabelecimento de prioridade de infrra-estrutura, equipamentos e serviços a serem instalados. Para tal, a identificação, reconhecimento e delimitação do que é rural e do que é urbano torna-se fundamental para que sejam implementadas as respectivas políticas conforme a pertinência de suas pastas.

A questão posta é saber como se estabelece a diferenciação entre o campo e a cidade e de que forma detectar os diferentes níveis de complementaridade realizados entre esses dois meios.

O IBGE constrói conceitos e definições para a elaboração dos Censos e atendimentos de outras demandas. A discussão na perspectiva técnica e teórica tem claras implicações políticas. No Brasil, vários municípios adotam a classificação das zonas rural e urbana, independente da característica da paisagem e da configuração social que elas assumem. Trata-se de uma questão séria que impõe a realização de levantamentos e estudos mais refinados capazes de garantir uma delimitação mais próxima do real considerando o número de habitantes, a densidade demográfica, a presença absoluta e relativa de atividades ligadas ao setor terciário, a circulação de capitais, entre outros. No Brasil, toda sede de município e de distrito é considerada cidade, segundo o IBGE. São cidades e vilas, muitas delas com características rurais, classificadas entretanto, como espaço urbano, por força da legislação. Trata-se do Decreto Lei 311, de 1938, instituído durante a vigência do Estado Novo. O IBGE define, desde 1991, três categorias de áreas urbanas: urbanizadas, não-urbanizadas e urbanas-isoladas. Quanto ao rural, as categorias são extensão urbana, povoado, núcleos e outros. A classificação oficial não descarta as discussões no que tange à ruralidade. $\mathrm{O}$ enfoque clássico tratava o tema numa perspectiva chamada de dicotomica atribuindo ao rural a condição de espaço do tradicional e ao urbano, a condição de moderno.

Wanderley (2000) ao tratar a questão propõe uma nova ruralidade, assumindo três aspectos, considerando, antes de mais nada, o espaço e atividade realizada. Em seguida discute as partucularidades da nova ruralidade quando pergunta se o rurícula é conservador ou um sujeito social que resiste às imposições da globalização. Por fim aborda seu alcance espacial quando afirma que o rural pode estar também na cidade. Para a autora já não existem grandes diferenças entre os espaços rural e urbano nas sociedades desenvolvidas.

Essas três dimensões rompem com a leitura tradicional marcada pela dicotomia que estabelecia uma rígida separação do que seria rural e urbano, pressupondo uma linha divisória impondo limites.

O conceito de novo rural foi desenvolvido por Graziano da Silva (1996) quando associa a ideia de agricultura moderna à agroindústria e as atividades não agrícolas caracterizadas pela moradia, lazer, prestação de serviços. O autor recupera, mesmo que parcialmente, alguns pressupostos da teoria do continuum rural-urbano. Afirma que o meio rural brasileiro desempenha novas funções, independente das atividades agropecuárias e agroindustriais.

A pluriatividade compreendida como a combinação de todas as atividades agrícolas e não agrícolas exercidas por todos os membros do domicílio, sejam elas realizadas dentro ou fora das explorações agropecuárias complementares ou suplementares à composição da renda familiar tem sido objeto de interesse teórico que data do final do século XIX. O conceito aparece em Kautski (1968) estabelecendo comparação entre a grande propriedade e os pequenos agricultores, mostrando a possibilidade de coexistência dado aos avanços da industrialização da agricultura.Chayanov (1974) revela a presença da pluriatividade na realidade russa já na primeira metade do século XX.

Dentre outros autores que se dedicam ao tema, Alentejano (2000) e Carneiro (1998) trabalham o conceito de pluriatividade, partindo do pressuposto que o espaço rural não se define mais pela atividade agrícola, e que ele pode ser até uma representação do social. Discute, na perspectiva das relações campo-cidade, a pluriatividade do agricultor e não-agricultor no campo. 
O aprofundamento da questão induz à emergência e visibilidade de novos sujeitos sociais, implicando na separação entre o rural e o agrícola e na ocupação diversificada do rural e do urbano.

Cabe lembrar que as periferias das pequenas e médias cidades, bem como das metrópoles, apresentam paisagens urbanas com características tipicamente rurais. No bojo da discussão conceitual de busca de novas abordagens, a luta pela terra é uma permanência. Ela permeia os espaços rural e urbano, denunciando uma questão social de longa duração em nosso percurso histórico. $\mathrm{O}$ MST - Movimento dos Sem Terra, expandiu-se, acentuou a questão da terra. Hoje são várias as organizações surgidas a partir da luta pela terra para se viver seja no campo ou na cidade. Quanto à trajetória de luta pela terra no Brasil, Stedele (2009) é enfático ao dizer:

A questão da terra converte-se em tema nacional. A luta pela reforma agrária que antes se baseava apenas na ocupação de terras do latifúndio, agora ficou mais complexa. Temos que lutar contra o capital. Contra a dominação das empresas transnacionais. E a reforma agrária, deixou de ser aquela medida clássica: desapropriar grandes latifúndios e distribuir em lotes para os pobres camponeses. Agora, as mudanças no campo, para combater a pobreza, a desigualdade e a concentração de riquezas, depende de mudança não só da propriedade da terra, mas também do modelo de produção. E agora, os inimigos são também as empresas internacionalizadas, que dominam os mercados mundiais. Significa também que os camponeses dependerão cada vez mais das alianças com os trabalhadores da cidade para poder avançar nas suas conquistas.

Incorporando vários aspectos dos movimentos sociais ruralidade e urbanidade, enquanto argumento, convertem-se em conceitos, incorporados rapidamente às discussões de cunho teórico-metodológico (não está clara a frase). Persistem, mesmo que a contragosto dos modeladores de um novo formato desenvolvimentista. $\mathrm{O}$ contradiscurso não foi capaz de superar velhas práticas. $\mathrm{O}$ máximo que fez foi criar ilhas diferenciadas com melhores condições de emprego e renda através da utilização da modernização técnica.

\section{O RURAL E O URBANO SOB A PERSPECTIVA DO DESENVOLVIMENTO}

A complexidade da dinâmica demográfica brasileira, seu movimento e suas configurações animaram teóricos que retomaram as teses neomalthusianas na discussão sobre o perfil da família brasileira, controle familiar e planejamento da população. Por outro lado, a escalada da economia e a formação de um segmento de classe média no país, revigoraram a crença no desenvolvimento alcançado pelo processo de industrialização. As cidades, particularmente as capitais, foram escolhidas para receberem investimentos maciços na construção de pólos, distritos e complexos industriais. No contexto dessas políticas, decorreu uma expansão da malha das cidades com implantação de enormes conjuntos habitacionais capazes de alojar a transferência maciça de população. Fortes fluxos migratórios campo - cidade e inter-regional assentaram, em pouco tempo, enorme contingente demográfico nas cidades brasileiras, especialmente no Sudeste. A expansão das fronteiras agrícolas e a incorporação de novas tecnologias resultaram em aumento sucessivo de safras e melhor distribuição da produção garantindo substancial conquista de qualidade no setor de abastecimento. É o início de uma fase em que os problemas sociais brasileiros adquirem maior visibilidade e exigem explicações científicas pautadas em pressupostos teóricos e conceitos consistentes. Campo e cidade se interiorizam acompanhando a marcha do desmatamento.

As diversas abordagens explicativas do desenvolvimento exerceram peso preponderante sobre a adoção de políticas públicas no Nordeste, especialmente, as de cunho compensatório, dentre elas, as teorias clássicas que foram constantemente adotadas como modelo.

No Brasil, a teoria do desenvolvimento regional de maior vigor e pulso, liga-se à concepção desenvolvida por Perroux (1967). O autor parte do pressuposto que o crescimento econômico se processa de forma diferenciada, com algumas áreas ou setores encontrando fatores mais favoráveis sob a forma de recursos naturais combinados com situações institucionais, em um dado momento 
do tempo, que fazem emergir uma fase de crescimento econômico e prosperidade. Para o autor, a conseqüência natural seria desenvolvimento desigual, acentuado pelo funcionamento do efeito multiplicador diferenciado. O autor discute o conceito de pólo de crescimento e destaca um caráter seletivo do capital e afirma que o crescimento econômico não surge ao mesmo tempo e em toda parte.

Aplicado ao nosso país, denota-se que no Centro Sul do Brasil, a industrialização é atribuída à conjunção de vários fatores favoráveis, e apresenta papel propulsor da proliferação de cidades e instauração de um modo de vida urbano. Hoje, diversas questões, anteriormente restritas à análise regional, extrapolam os recortes clássicos que estabeleciam limites entre o rural e o urbano. Outros discursos inscrevem-se na perspectiva de reelaborar os conteúdos dos conceitos. Cabe ressaltar o desmonte paulatino da infra-estrutura do Estado em todos os setores, enfraquecendo-o. O programa de privatização fragilizou mais ainda o Estado. As teses pautadas no desenvolvimentismo apostavam na produção de espaço homogêneo capaz de equalizar o país quanto às oportunidades de acesso aos itens característicos da vida moderna. O desenvolvimentismo converteu-se em bandeira política, promessa de campanha, programa de governo. Enquanto meta oficial alterou substancialmente a territorialidade brasileira

O país atravessa um período de crescimento acelerado mesmo nos anos sessenta, quando, em termos internacionais, emerge a crise do modelo fordista de desenvolvimento, cuja principal característica foi a perda de eficácia, que era, na verdade, a face exposta do complexo modo de regulação. A crise incitou o reajuste estrutural na esperança de interromper a acelerada destruição dos quadros de reprodução social. No Brasil, o desenvolvimentismo sucumbiu, não ultrapassou os anos setenta do século XX.

A crise favorece a reestruturação produtiva que tem como base o princípio da inovação baseado no conceito de uma destruição criadora, capaz de gerar o progresso.

É difícil, para os pesquisadores e dirigentes interessados no desenvolvimento, medir a evolução do sistema produtivo deste final de século. As bases do processo de desenvolvimento econômico e regional mudaram profundamente, e um novo ponto de partida se delineia nos anos noventa. A passagem para novo regime de acumulação acompanha-se de mudanças fundamentais multiformes no modo de produção e de consumo, nas transações e nos mecanismos institucionais de regulação das relações sociais. Induzem à reestruturação espacial da sociedade inteira com uma redefinição do conteúdo ideológico dos espaços, o estabelecimento de nova divisão social e espacial do trabalho e criação de novos espaços de produção e de consumo.

Neste sentido, o sistema produtivo fratura-se, dando origem a um mosaico de territórios diferenciados, Benko (1996), tanto na acepção do espaço regional como também na forma metropolitana, com seus sucessivos recortes fragmentários. Em contrapartida, as poucas formulações teóricas atualizadas, voltam-se à análise do espaço como expressão do arranjo sociopolítico nacional com a devida distribuição de atividades, infra-estruturas, equipamentos e serviços.

São análises que persistem nas abordagens de ciências tradicionais como a Geografia e a Economia. Seus enfoques privilegiam a dinâmica espacial brasileira revelando uma expressiva ampliação da área ocupada, formando um grande escudo produtivo comandado por complexas operações do capital que avança na direção Sul/Norte, integrando enormes porções do Centro-Oeste e da Amazônia e desintegrando parcelas significativas do espaço como o nordestino. Quanto ao Nordeste, cabe lembrar tratar-se do espaço regional brasileiro, marcado pela prática secular de regionalismo. Ao identificar os recortes e as delimitações decorrentes da enorme competição que se trava no interior do país e através das regiões com seus núcleos urbanos tradicionais, podem ser percebidos diferentes momentos/movimentos de produção da cidade reforçando sua condição de lugar, de territorialidade, socialmente construído. Verifica-se, ao mesmo tempo, que a intensificação de relações com espaços à sua volta, induzem a um intenso processo de competição metropolitana que acirra a competição urbana quanto à função de comando das principais cidades do país. 
No tocante ao Nordeste brasileiro, salvo as grandes cidades e algumas de porte médio, o urbano resultou mais do peso da agricultura e da pecuária na organização de seu território impedindo a criação de um espaço regional integrado. Essas cidades transformaram-se, em pouco tempo, em enormes bolsões de pobreza. Com o advento da globalização coube ao Nordeste, através do turismo, a exploração exacerbada do potencial paisagístico de seu litoral. Essa reinserção da região na divisão internacional do trabalho no contexto da economia agora flexibilizada põe em xeque o estabelecimento de fronteiras na discussão do rural e do urbano sob a ótica da teoria do desenvolvimento. Esse processo vivenciado pelo Nordeste remete à discussão teórica da urbanização do litoral e manutenção de atividades agrícolas residuais. São criados territórios temáticos em torno de atividades típicas do mundo rural, nas proximidades do litoral com capacidade de atrair turistas em visitas a canaviais, engenhos, alambiques, etc.

Hoje, o Nordeste acompanha sem muito interesse a recriação da SUDENE, desenhada agora com outro perfil. Segundo seus opositores, trata-se de uma instituição frágil, bem diferente daquela dos primórdios dos anos sessenta, quando em plena operação, alterava as estruturas clássicas do rural e do urbano na região. O Nordeste se expande por todo território nacional. Conforme Martins (1994), os imigrantes nordestinos habitam as periferias das periferias metropolitanas nacionais, aqueles lugares sem infra-estrutura, sem condições de habitação, cuja renda obtida pela fragmentação do solo urbano é menor. Mas nem sempre as periferias são os lugares forçados de habitação dos imigrantes. Os centros das grandes metrópoles também vão sendo ocupados por grupos recentes dessas populações, ou por seus descendentes, cuja inserção social é ainda mais degradante, constituindo-se em uma realidade que vai se reproduzindo por todo o país. Silva(2005, p. 103) também identifica na "expansão das fronteiras urbanas" como da Região Metropolitana de Fortaleza (RMF) um conflito e um confronto pela habitação que emerge com a massiva chegada de imigrantes na periferia.

No Nordeste, o urbano resultou mais do peso da agricultura e da pecuária na organização do espaço. O sistema de cidades decorrente da lavoura canavieira e interiorização das fazendas de gado recebeu grande impulso com o advento da cultura do algodão na segunda metade do século passado. Engenhos e fazendas deram origem às cidades localizadas às margens e fozes dos rios, pontuando o litoral com pequenos núcleos. A consolidação dos portos mais importantes deu-se com o advento da ferrovia que favoreceu o estabelecimento de uma economia primário/exportadora que propiciava uma intensa dinâmica à cidade portuária que organizava extensas bacias de colheita de produção primária ligada ao extrativismo, à criação intensiva e exploração das drogas do sertão. A cana-de-açúcar gerou um sistema urbano na área correspondente à Zona da Mata, que se estende do sul do Rio Grande do Norte até o Nordeste da Bahia. O algodão permitiu a dispersão da cidade pelas vastas extensões da superfície sertaneja. No Ceará é esse tipo de cidade que vai dominar a paisagem. Pequenos núcleos constituídos como ponto de apoio onde os viajantes e vaqueiros apeavam em suas aventuras pelo sertão. A inexpressividade da cana-de-açúcar no Ceará prende-se a uma determinação de natureza física, ou seja, a ausência de uma zona de intensa pluviosidade como a Zona da Mata, constituída de solos bem característicos.

\section{CONSIDERAÇÕES FINAIS}

A passagem de país agrícola para país industrializado, mantendo-se, entretanto, subdesenvolvido, aguçou o quadro de desigualdades e converteu o urbano em tema emblemático das grandes questões nacionais.

No Brasil, o processo de industrialização modificou as estruturas internas do país, no que se refere à sua realidade espacial. Essas mudanças foram extremamente bruscas, ocasionando a transferência de levas e levas de migrantes para as grandes cidades. O processo de fragmentação metropolitana, associado a uma descentralização da indústria, que busca nas cidades menores mão de obra mais barata, provoca um enfraquecimento do acirramento da luta sindical, redução dos custos 
de produção e, logicamente, maior lucratividade. De forma concomitante, dá-se o reflorescimento de antigas cidades e o crescimento de outras. $\mathrm{O}$ rápido processo de urbanização está intimamente ligado à industrialização do Brasil que ocorreu de forma concentrada no Sudeste, especialmente na cidade de São Paulo. Segundo Moreira (1981. p. 101):

O acelerado crescimento econômico agilizará o processo de expansão das relações capitalistas sobre o espaço, desvinculando organicamente o homem de seus laços com as condições materiais de trabalho, expropriando a terra ao campesinato e os meios de produção aos artesãos e forçando a concentração dos homens na fortaleza do capital, a cidade. O espaço concentrado que se inicia com a destruição da pequena produção pela manufatura, agora se completa. Os campos se despovoam e as cidades engordam e se multiplicam.

Nessa fase do processo se estrutura uma hierarquia urbana nacional que reforça o papel de várias cidades (especialmente as capitais estaduais), que se transformam em grandes centros de redistribuição de produtos industrializados e centros coletores da produção agrícola de suas respectivas áreas de influência. Fortaleza é um exemplo típico dessa situação. O papel assumido pelo setor terciário justifica em parte seu crescimento e a influência que ela exerce sobre um vasto espaço que se estende além dos limites estaduais. Os fluxos migratórios para Fortaleza têm sido intensos e o aumento dos índices de pobreza urbana, mostram-se alarmantes.

No Nordeste, a indústria ainda não encontrou a expressão que tem no Centro-Sul do país. O quadro, malgrado à sua dinâmica, permanece apresentando sérias disparidades como ressalta Oliveira. (1978, p.7576):

no momento, pois, em que a expansão do sistema capitalista no Brasil tem seu lócus na 'região' Sul comandada por São Paulo, o ciclo toma espacialmente a forma de destruição das economias regionais, ou das 'regiões'. Esse movimento dialético destrói para concentrar, e capta o excedente das outras 'regiões' para centralizar o capital. O resultado é que, em sua etapa inicial, a quebra das barreiras inter-regionais, a expansão do sistema de transporte facilitando a circulação nacional de mercadorias, produzidas agora no centro de gravidade da expansão do sistema, são em si mesmas, tantas outras formas de movimento de concentração; e a exportação de capitais das 'regiões' em estagnação são a forma do movimento de centralização. Aparentemente, pois, sucede de início, uma destruição das economias 'regionais', mas essa destruição não é senão uma das formas de expansão do sistema em escala nacional.

Nos anos noventa, a globalização da economia extrapola esse processo e ultrapassa os limites do estado/nação. O capital transnacional impulsiona os mais variados setores produtivos, intensifica o ramo de prestação de serviços e coloca, principalmente, a cidade em conexão com o mundo. Novos portos, aeroportos, conglomerados, novos blocos mundiais - União Européia, Mercosul, Nafta - novas possibilidades. Portas e barreiras se abrem e se impõem na contemporaneidade da mundialização. O turismo e o lazer, sozinhos ou associados, agora também com novo formato, assumem papel de destaque na economia brasileira. O campo é repaginado pelo turismo com a instalação de hotéis-fazenda, trilhas ecológicas, esportes radicais, experiências com lavoura orgânica, etc. Com vasto litoral ensolarado, vários estados investem somas significativas para carrear cada vez mais, maior número de turistas nacionais ou estrangeiros. As cidades se equipam, estendem sua infra-estrutura para os espaços vizinhos e criam ou recriam lugares, destinando-os à condição de novos territórios do turismo. Acirra-se a competição entre os estados. O turismo intermedia o rural e o urbano estendendo seus tentáculos a várias porções do território. É uma atividade que surge como a grande possibilidade de geração de emprego e renda, de inserção de um amplo segmento da população ligada ao folclore, ao artesanato, às tradições, à confecção e prestação de serviços especializados. 


\section{REFERÊNCIAS BIBLIOGRÁFICAS}

ALENTEJANO, Paulo Roberto. O que há de novo no rural brasileiro? Terra Livre, n. 15, São Paulo, 2000. ANDRADE, Manuel Correia de. A Estrutura Portuária e a Organização do Espaço no Brasil. Anais da Associação dos Geógrafos Brasileiros, Vol. XIX, São Paulo, AGB, 1978.

ANDRADE, Manuel Correia de. A Terra e o Homem no Nordeste. $3^{\text {a }}$ ed. São Paulo: Brasiliense, 1974.

ANDRADE, Manuel Correia de. Processo de Ocupação do Espaço Regional do Nordeste. Estudos Regionais, Recife, SUDENE/CPR, 1975.

AZEVEDO, Aroldo. As cidades. O Brasil a terra e o homem, Vol. II - A Via Humana. São Paulo: Companhia Editora Nacional/Edusp, 1970.

BENKO, George. Economia, espaço e globalização na aurora do século XXI. São Paulo: HUCITEC, 1996.

CARNEIRO, Maria José. Ruralidade: novas identidades em construção. Estudos Sociedade e Agricultura, Rio de Janeiro, CPDA/UFRRJ, n. 11, out., 1998.

CHAYANOV, A. V. La organización de la unidad econômica campesina. Buenos Aires: Ediciones Nueva Vision, 1074.

CNBB. Solo Urbano e Ação Pastoral. 2a ed. São Paulo: Edições Paulinas, n. 23, 1982.

GRAZIANO DA SILVA, José. A nova dinâmica da agricultura brasileira. Campinas: Instituto de Economia (IE/UNICAMP), 1996.

HARVEY, David. A justiça Social e a Cidade. São Paulo: HUCITEC, 1980.

IBGE. Divisão do Brasil m Regiões Funcionais Urbanas. Rio de Janeiro. 1972.

IBGE. Pesquisa Nacional por Amostra de Domicílios - 1978. Área Metropolitana de Fortaleza, Vol. 3, Tomo 14, Rio de Janeiro, 1980.

IBGE. Sinopse Preliminar do Censo Demográfico. Ceará - Rio de Janeiro. 1980.

KAUTSKY, K. A questão agrária. Rio de Janeiro: Laemmert, 1968.

MARTINS, José de Souza. O poder do atraso: ensaios da sociologia da história lenta. São Paulo: HUCITEC, 1994.

MOREIRA, Ruy. O que é geografia? São Paulo: Brasiliense, Coleção Primeiros Passos. 1981.

OLIVEIRA, Francisco de. Elegia para uma Re(li)gião. Rio de Janeiro: Paz e Terra, 1978.

PERROUX, François. A economia do século XX. Porto: Herder, 1967.

ROCHEFORT, Michel. A problemática do Espaço nos Países do Terceiro Mundo. Trad. de José Borzacchiello da Silva. Fortaleza, AGB - Diretoria de Fortaleza, 1981 (datil.).

SANTOS, Milton. Economia Espacial: Críticas e Alternativas. São Paulo: Hucitec, 1979.

SANTOS, Milton. A urbanização brasileira. São Paulo: HUCITEC, 1993.

SANTOS, Milton. Pobreza Urbana. São Paulo/Recife: Hucitec, 1978.

SILVA, José Borzacchiello. Região Metropolitana de Fortaleza. In: SILVA, J. B.; CAVALCANTE, T. C.; DANTAS, E. W. C. (Orgs.). Ceará: um novo olhar geográfico. Fortaleza: Edições Demócrito Rocha, 2005. SUDENE. Vinte Anos. Recife, 1980.

WANDERLEY, Maria Nazareth B. A emergência de uma nova ruralidade nas sociedades avançadas: o rural como espaço singular e ator coletivo. Estudos Sociedade e Agricultura, Rio de Janeiro, n. 15, CPDA/ UFRRJ, out., 2000.

Trabalho enviado em novembro de 2011

Trabalho aceito em dezembro de 2011 